\title{
The future of robotic liver surgery
}

\section{Pier Cristoforo Giulianotti}

Division of General, Minimally Invasive and Robotic Surgery, University of Illinois at Chicago, Chicago, IL, USA

Correspondence to: Prof. Pier Cristoforo Giulianotti, MD, FACS. UIC LIoyd Nyhus Professor in Surgery, Division of General, Minimally Invasive and Robotic Surgery, University of Illinois at Chicago, 840 S Wood Street, Suite 435 E, Clinical Sciences Building, Chicago, IL 60612, USA.

Email: piercg@uic.edu.

Provenance and Peer Review: This article was commissioned by the editorial office, Hepatobiliary Surgery and Nutrition. The article did not undergo external peer review.

Comment on: Melstrom LG, Warner SG, Woo Y, et al. Selecting incision-dominant cases for robotic liver resection: towards outpatient hepatectomy with rapid recovery. Hepatobiliary Surg Nutr 2018;7:77-84.

Submitted Dec 04, 2019. Accepted for publication Mar 03, 2020.

doi: 10.21037/hbsn.2020.03.17

View this article at: http://dx.doi.org/10.21037/hbsn.2020.03.17

I read with great interest the article published by Melstrom et al. (1) from Dr. Fong's team. I found several interesting points worthy of discussion.

The dominant role of the "access" incision in liver resections is a very important concept during the final patient's recovery.

We should make a special effort to offer minimally invasive surgery (MIS) surgery to these patients, especially in difficult posterior segments where laparoscopy is challenging (2). Unfortunately, we do not have prospective/ randomized data to support the thesis that the robot, in difficult segments, is performing better than laparoscopy.

Even in the retrospective study reported by Dr. Fong's team (1), more than $50 \%$ of patients were less technically difficult anterior segments, and there is no comparison of postoperative outcomes between the two groups (anterior and posterior segments). However, we can see that the conversion rate was higher for the difficult segments $(12 \%)$.

The dream goal of MIS liver surgery, performed on an outpatient basis, is a fascinating perspective that I totally share, even though we should proceed with caution.

Atypical resections (unless they are minor wedge) are not immune from the risk of complications (delayed bleeding/leaks). An observation period of at least 2448 hours could be a reasonable compromise.

Short or ultrashort hospital stay is a great advantage for MIS patients, and it also has an important economic impact.
Our group has specifically studied costs related to robotics in comparison to open liver surgery. This study was conducted by an external evaluator, and concluded that robotics is cost effective even when no selection is made between major and minor hepatectomies (3).

I do believe also that one of the most important roles of robotics is to expand the indications of MIS in complex major hepatectomies and procedures requiring fine dissection in the hilum, or sophisticated microsurgical work (such as intrahepatic biliary reconstruction).

In major liver resections, the "liver regeneration" disease is not the only important factor for recovery. The final healing is the result of multiple contributing factors (amount of resected liver, volume and quality of the residual parenchyma, quality of surgery, blood loss, surgical wounds, comorbidities, etc.).

The perspectives of robotics in liver surgery are not only based on improved instrumentation, but also on the overall development of the digital platform [augmented reality, artificial intelligence (AI)]. Digital pathology, accurate assessment of margins, minimizing risk of collateral damages based on perfect $3 \mathrm{D}$ reconstructions, are some of the next to come, behind the scene achievements (4). This is why we believe the future of MIS is entirely connected with the development of robotics. The combination of an easier and friendlier learning curve, a better instrumentation and the digital AI platform will make robotics the standard MIS liver approach of the future. 


\section{Acknowledgments}

Funding: None.

\section{Footnote}

Conflicts of Interest: The author has completed the ICMJE uniform disclosure form (available at https://hbsn.amegroups. com/article/view/10.21037/hbsn.2020.03.17/coif). The author is a consultant for Medtronic (Covidien) and receives consulting fees for this work. He is a surgical proctor for Intuitive Surgical and receives proctoring fee payments for this work. He also participates in the Case Observation Program at his institution, for which their department receives payments for case observations from Intuitive Surgical. PCG has a consultant agreement with Covidien Medtronic and Ethicon Endosurgery, and he also has an institutional agreement (University of Illinois at Chicago) for training with Intuitive.

Ethical Statement: The author is accountable for all aspects of the work in ensuring that questions related to the accuracy or integrity of any part of the work are appropriately investigated and resolved. The study was approved by the Institutional Review Board of the Ohio State University.

Open Access Statement: This is an Open Access article distributed in accordance with the Creative Commons Attribution-NonCommercial-NoDerivs 4.0 International License (CC BY-NC-ND 4.0), which permits the noncommercial replication and distribution of the article with the strict proviso that no changes or edits are made and the original work is properly cited (including links to both the formal publication through the relevant DOI and the license). See: https://creativecommons.org/licenses/by-nc-nd/4.0/.

\section{References}

1. Melstrom LG, Warner SG, Woo Y, et al. Selecting incision-dominant cases for robotic liver resection: towards outpatient hepatectomy with rapid recovery. Hepatobiliary Surg Nutr 2018;7:77-84.

2. Kawaguchi Y, Fuks D, Kokudo N, et al. Difficulty of Laparoscopic Liver Resection: Proposal for a New Classification. Ann Surg 2018;267:13-7.

3. Daskalaki D, Gonzalez-Heredia R, Brown M, et al. Financial Impact of the Robotic Approach in Liver Surgery: A Comparative Study of Clinical Outcomes and Costs Between the Robotic and Open Technique in a Single Institution. J Laparoendosc Adv Surg Tech A 2017;27:375-82.

4. Oldhafer KJ, Peterhans M, Kantas A, et al. Navigated liver surgery : Current state and importance in the future. Chirurg 2018;89:769-76.

Cite this article as: Giulianotti PC. The future of robotic liver surgery. HepatoBiliary Surg Nutr 2020;9(4):546-547. doi: 10.21037/hbsn.2020.03.17 